\title{
GMR
}

\section{Cloning and expression of class I chitinases in Hami melon after Penicillium infection}

\author{
F.Y. Jiang, B.B. Shui, F.X. Tang and C.H. Shan \\ Food College of Shihezi University, Shihezi, China \\ Corresponding author: C.H. Shan \\ E-mail: sch_0909@163.com
}

Genet. Mol. Res. 16 (1): gmr16019085

Received August 17, 2016

Accepted January 18, 2017

Published February 8, 2017

DOI http://dx.doi.org/10.4238/gmr16019085

Copyright (C) 2017 The Authors. This is an open-access article distributed under the terms of the Creative Commons Attribution ShareAlike (CC BY-SA) 4.0 License.

\begin{abstract}
Chitinases are important disease-related proteins that play critical roles in plant defense against disease. To investigate the function of chitinases in the resistance of Hami melon to Penicillium infection, the gene encoding chitinases, HmCHT-2, was cloned and RTPCR was used to measure expression levels of HmCHT-2. When the Hami melon was infected by Penicillium sp after $0,12,36,48,60$, and $72 \mathrm{~h}$. The results showed that comparing to the control group, the time of expression levels reaching to the peak delayed and the expression levels maintained at a significantly high level for a longer time. These results suggest that HmCHT-2 may contribute to the defense of Hami melon against fungal infection.
\end{abstract}

Key words: Chitinases; RT-PCR; Penicillium infection; HmCHT-2

Genetics and Molecular Research 16 (1): gmr16019085 


\section{INTRODUCTION}

Hami melon, a cultivar of muskmelon and important food crop in China, is susceptible to infection by pathogenic fungi during postharvest storage, which may lead to spoilage. Penicillium is one of the major genera of pathogenic fungi involved in the deterioration of the fruit (Chen et al., 2012; Liu et al., 2013). Prolonging the limited postharvest lifespan of Hami melon has been a significant research topic in China, where a number of studies have been aimed at the control of pathogenic infections (Dangl and Jones, 1998; Guo et al., 2007). Systemic acquired resistance is an important component of disease resistance that contributes significantly to plant health (Ryals et al., 1994). Some treatments have been found to improve disease resistance in Hami melon. For example, the application of natamycin in combination with bilayer films consisting of chitosan and polyethylene wax have been shown to inhibit the growth of Alternaria alternate and Fusarium semitectum on the melon surface (Cong et al., 2007), while sodium silicate treatment has been found to inhibit the growth of Trichothecium roseum (Bi et al., 2006).

Chitin is a structural component of the cell wall of many phytopathogenic fungi, which indicates that plant chitinases are typical pathogenesis-related proteins related to the innate defense against plant diseases (Kombrink et al., 1988; Stintzi et al., 1993). Recent researches have proven that chitinases contribute to pathogen resistance in plants (Taira, 2010; Graça et al., 2016). In plants, chitinases are hydrolytic enzymes that are involved in many aspects of plant growth and development, including cell wall metabolism and disease resistance (Sharma et al., 2011). Some of them are not affected by pathogenic fungus or stress and related to plant growth and development. For example, BC15/OsCTL1, a class II chitinase-like protein, mediated cellulose biosynthesis and cell wall remodeling in rice (Wu et al., 2012), while some chitinases can be induced by phytopathogenic fungi and contribute to disease resistance and stress. For example, when upland rice was exposed to various abiotic stresses (including drought, salt and low temperature), the expression levels of DIP3 encoding a chitinase III protein accumulated rapidly (Guo et al., 2013). Furthermore, the overexpression of the $R C H 10$ chitinases gene via agrobacterium-mediated transformation conferred resistance to fungal infection by Botrytis cinerea in Lilium (González et al., 2015).

However, research on chitinases in Hami melon is limited. An understanding of the structure and biological function of chitinases in this fruit will provide a theoretical basis for its response to phytopathogenic fungi, and may also provide an alternative solution for prolonging its post-harvest storage life.

\section{MATERIAL AND METHODS}

\section{Sample collection}

The Penicillium strain used in this study was isolated from Hami melon surface in previous study by our lab. The Penicillium strain was grown in the potato medium $(2 \%$ glucose, $2 \%$ agar, $20 \%$ potato) and then cultivated at $28^{\circ} \mathrm{C}$ until a large quantity of spores were produced. The Penicillium spores were harvested by using sterile water flushing and the spores suspensions were diluted with sterile water to obtain $1 \times 10^{5}$ spores $/ \mathrm{mL}$ dilutions.

Genetics and Molecular Research 16 (1): gmr16019085 


\section{Plant material}

The Hami melons used in this study were late-maturing, in which reducing sugar content was $11-12 \%$ and no obvious damage was discovered. Six melons, about $3 \mathrm{~kg}$ per one, were divided into two groups containing 3 parallels. Six and eight incisions were made on every fruit using a sterile hole-puncher $(1 \mathrm{~cm}$ deep by $1 \mathrm{~cm}$ in diameter) in the first and the second groups, respectively (Figure 1). Then $10 \mu \mathrm{L}$ Penicillium spore suspensions $\left(1 \times 10^{5}\right.$ spores $\left./ \mathrm{mL}\right)$ was added into three of six wounds in each melon in the first group and four of eight wounds in each melon in the second group, while $10 \mu \mathrm{L}$ sterile water was added into other wounds in each melon in the first group and the second group as control. The melons were then covered with plastic wrap and maintained at room temperature (about $25^{\circ} \mathrm{C}$ ). After inoculation for 0, 12, 24, 36, 48, 60, and $72 \mathrm{~h}$ (Figure 2), 3 parallel samples around the incision points from the first and the second groups were drawn and immediately frozen in liquid nitrogen.

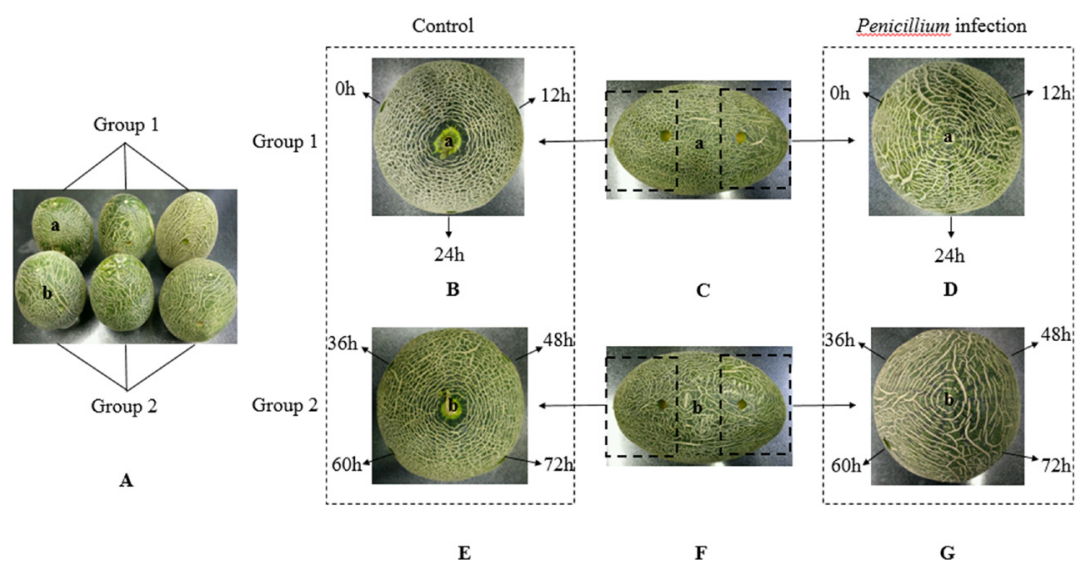

Figure 1. Incisions of Hami melon. A. photographs of two groups containing 3 parallels; B. C. D. incisions on one Hami melon in Group 1; E. F. G. incisions on one Hami melon in Group 2.

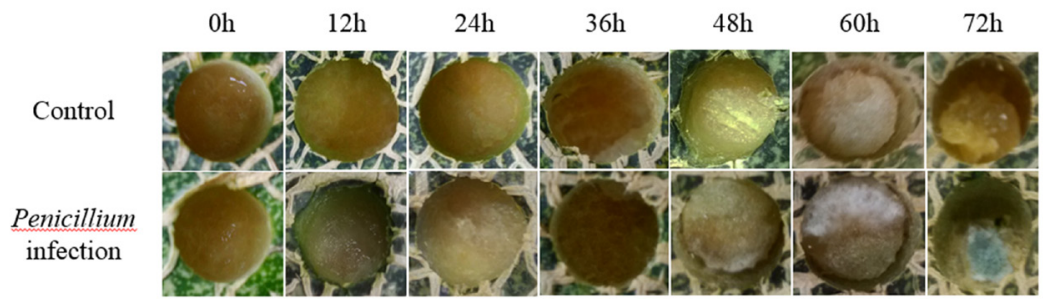

Figure 2. Effects of Penicillium infection on Hami melon.

\section{Screening of chitinase genes}

We had previously established the transcriptome of Hami melon prior to and after infection with the Penicillium strain using an Illumina Hiseq 2000 sequencing system (ABlife Inc., Wuhan, China). We also analyzed differentially expressed genes at different time 
points after inoculation (0, 48 and $60 \mathrm{~h}$ ) using RNA-Seq technique (Shan, 2015). Sixteen differentially expressed chitinase genes were identified (Table 1). Among them, the CL2231. Contig2_QHMG chitinase gene displayed an observably higher expression level then others and was selected in this study.

Table 1. Differentially expressed genes of chitinase in Hami melon.

\begin{tabular}{l|c|c|c|l}
\hline GeneID & $0 \mathrm{~h}$ RPKM & $48 \mathrm{~h}$ RPKM & $60 \mathrm{~h}$ RPKM & BLASTnr \\
\hline Unigene8343_QHMG & - & 76.15 & 76.15 & gi|312191345|gb|ADQ43720.1| class I chitinase [Casuarina equisetifolia] \\
\hline Unigene8344_QHMG & - & 148.62 & 148.62 & gi|449508755|ref|XP_004163402.1| endochitinase-like [Cucumis sativus] \\
\hline Unigene22455_QHMG & - & 5.71 & 1.49 & gi|8272386|dbj|BAA96445.1| endo-chitinase class III [Pyrus pyrifolia] \\
\hline CL4824.Contig1_QHMG & 4.39 & 826.96 & $1,607.41$ & gi| $449456357 \mid$ ref|XP_004145916.1| acidic endochitinase-like [Cucumis sativus] \\
\hline CL2231.Contig2_QHMG & 107.54 & $14,493.83$ & $25,398.46$ & gi|23496435|dbj|BAB40817.2| endochitinase MCHT-2 [Cucumis melo] \\
\hline CL2231.Contig1_QHMG & 2.45 & 324.35 & 608.04 & gi|449508755|ref|XP_004163402.1| endochitinase-like [Cucumis sativus] \\
\hline CL4824.Contig2_QHMG & 0.83 & 73.74 & 95.46 & gi|7595839|gb|AAF64474.1| chitinase 1 [Cucumis melo] \\
\hline Unigene17882_QHMG & 2.61 & 34.10 & 46.15 & gi|449454971|ref|XP_004145227.1| endochitinase PR4-like [Cucumis sativus] \\
\hline Unigene17906_QHMG & 3.29 & 34.60 & 33.09 & gi|449457929|ref|XP_004146700.1| acidic mammalian chitinase [Cucumis sativus] \\
\hline Unigene13259_QHMG & 302.10 & $1,266.18$ & $1,799.97$ & gi|5919201|gb|AAD56239.1| class III chitinase [Benincasa hispida] \\
\hline Unigene19961_QHMG & 17.67 & 5.10 & 4.65 & gi|449433057|ref|XP_004134314.1| acidic endochitinase-like [Cucumis sativus] \\
\hline Unigene29851_QHMG & 7.47 & 1.47 & 2.65 & gi|449503856|ref|XP_004162209.1| chitinase-like protein 2-like [Cucumis sativus] \\
\hline Unigene16405_QHMG & 8.92 & 1.45 & 0.58 & gi|13548699|dbj|BAB40818.1| endochitinase MCHT-3 [Cucumis melo] \\
\hline Unigene18657_QHMG & 26.43 & 3.82 & 3.60 & gi|449503856|ref|XP_004162209.1| chitinase-like protein 2-like [Cucumis sativus] \\
\hline CL726.Contig4_QHMG & 6.28 & 0.75 & 0.21 & gi|13548699|dbj|BAB40818.1| endochitinase MCHT-3 [Cucumis melo]
\end{tabular}

\section{Extraction and quantification of total RNA}

RNA extraction was performed with the Trizol protocol according to the Qiagen Plant RNA Extraction Kit 74903 manual. The quantity and quality of RNA were determined by ultraviolet light absorbance and confirmed by gel electrophoresis, which contained $1.2 \%$ agarose.

\section{Synthesis of first strand of cDNA}

First-strand cDNA was synthesized by using $2 \mu \mathrm{g}$ RNA, random primers and RNase inhibitors, and so forth, which had a final volume of $10.5 \mu \mathrm{L}$.

\section{Cloning and sequencing of gene encoding chitinases}

Based on our previously obtained Hami melon transcriptome library, the following primers were designed and synthesized to amplify the chitinase gene: GAAACAAACACAACAAAATCACAAAGG(forwardprimer)andGGGAGGGTATATATTA AAAAATATG (reverse primer). The 50- $\mu \mathrm{L}$ reaction mixtures consisted of: $34.8 \mu \mathrm{L} \mathrm{H}_{2} \mathrm{O}, 10$ $\mu \mathrm{L}$ buffer, $1 \mu \mathrm{L}$ dNTP, $1 \mu \mathrm{L}$ forward primer, $1 \mu \mathrm{L}$ backward primer, $2 \mu \mathrm{L}$ template, and $0.2 \mu \mathrm{L}$ Taq polymerase. The thermal profile consisted of: $94^{\circ} \mathrm{C}$ denaturation for $3 \mathrm{~min}, 39$ cycles of $94^{\circ} \mathrm{C}$ for $30 \mathrm{~s}, 51^{\circ} \mathrm{C}$ for $40 \mathrm{~s}, 72^{\circ} \mathrm{C}$ for $45 \mathrm{~s}$ and a final extension at $72^{\circ} \mathrm{C}$ for $7 \mathrm{~min}$.

The PCR product was analyzed using $1 \%$ agarose gel electrophoresis and then cloned into a pMD 18T vector (TaKaRa) for DNA sequencing. A BLAST search on the NCBI Genbank was performed using the DNA sequences.

\section{Bioinformatic analysis}

The open reading frame (ORF) and the encoded amino acid sequence were 
analyzed using ORF Finder on NCBI (http://www.ncbi.nlm.nih.gov/gorf/orfig.cgi). The physiochemical properties, hydrophilicity/hydrophobicity, signal peptide, secondary structure and transmembrane structure of the resultant protein were analyzed by using ProtParam (http://web.expasy.org/protparam/), ProtScale (http://web.expasy.org/protscale/), SignalP V.3.0 Server (http://www.cbs.dtu.dk/services/SignalP/), SOPMA (https://npsaprabi.ibcp.fr/cgi-bin/npsa_automat.pl?page=/NPSA/npsa_sopma.html) and TMHMM Server V. 2.0 (http://www.cbs.dtu.dk/services/TMHMM/), respectively. Protein tertiary structure were predicted by using SWISS-MODEL. The subcellular localization of the protein was predicted using ProtComp V. 9.0 (http://linux1.softberry.com/berry.phtml?grou $\mathrm{p}=$ programs\&subgroup $=$ proloc $\&$ topic $=$ protcompan $)$ and the PredictProtein service $(\mathrm{https}: / /$ www.predictprotein.org/). The amino acid sequence of the protein encoded by the longest ORF was analyzed using BLASTp on NCBI. The sequences with high similarity were used to construct a phylogenetic tree by using MEGA 5.0.

\section{Analysis of gene expression}

Based on the sequence of the target gene, the following primers were designed for real-time quantitative PCR analysis using Primer Express Software V. 2.0: GAAGAAACAATGGCTGCCCA (forward primer) and TTGTCCCCAATAGATGGCGA (reverse primer). The melon GAPDH gene was used as an internal reference (forward primer: CTTTCCGTGTTCCTACCGTT; reverse primer: CAGTGTACCCCAAAATTCCC). Realtime quantitative PCR was performed using cDNA obtained from RT-PCR and the amplification product was detected using fluorescent dye staining. The reaction mixture consisted of: $5 \mu \mathrm{L}$ $\mathrm{H}_{2} \mathrm{O}, 8 \mu \mathrm{L} 2 \mathrm{X}$ SYBR GREEN PCR mix, $1 \mu \mathrm{L}$ forward primer, $1 \mu \mathrm{L}$ backward primer, and 1 $\mu \mathrm{L}$ cDNA. The reaction was mixed well and placed in an ABI ViiA7 Real Time PCR System (Applied Biosystems) for amplification. The thermocycle consisted of $95^{\circ} \mathrm{C}$ pre-denaturation for $2 \mathrm{~min}, 40$ cycles of $94^{\circ} \mathrm{C}$ for $10 \mathrm{~s}, 60^{\circ} \mathrm{C}$ for $10 \mathrm{~s}$ and $72^{\circ} \mathrm{C}$ for $40 \mathrm{~s}$. The relative changes in gene expression ports was analyzed by the $2^{-\Delta \Delta C t}$ method (Livak and Schmittgen, 2001). The results were compared using variance analysis in SPSS V. 17.0.

\section{RESULTS}

\section{Cloning and sequencing of gene encoding chitinases}

A 1011-bp gene fragment was amplified and the agarose gel electrophoresis result was shown in Figure 3. The BLASTp results indicated that the cloned sequence belonged to family 19 chitinases, and had 98\% similarity with the chitinases of Cucumis melo (muskmelon: LOC103485181). The gene was named HmCHT-2 and submitted to NCBI with the accession No. KX083346.

\section{Sequence analysis of gene encoding Hami melon chitinases HmCHT-2}

To investigate the features of the chitinases, number of amino acids, molecular weight, theoretical isoelectric point, fat index, and grand average of hydropathy were predicted by using ProtParam and ProtScale. Results were shown in Table 2. The prediction of protein tertiary structure is shown in Figure 4.

Genetics and Molecular Research 16 (1): gmr16019085 


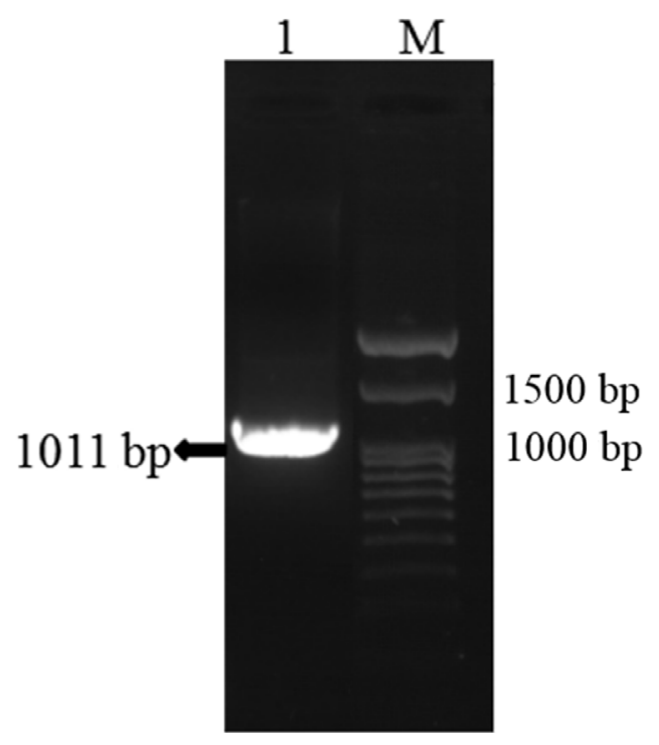

Figure 3. Electrophoresis of PCR products.

Table 2. Physical and chemical properties prediction of Hami melon chitinases HmCHT-2.

\begin{tabular}{l|c|l}
\hline Analysis index & Value & Prediction software \\
\hline Number of amino acids & 312 & ProtParam (http://web.expasy.org/protparam/) \\
\hline Molecular weight & $33.81 \mathrm{kU}$ & ProtParam (http://web.expasy.org/protparam/) \\
\hline Theoretical isoelectric point & 8.42 & ProtParam (http://web.expasy.org/protparam/) \\
\hline Fat index & 51.70 & ProtParam (http://web.expasy.org/protparam/) \\
\hline Grand average of hydropathy & 0.435 & ProtScale (http://web.expasy.org/protscale/) \\
\hline
\end{tabular}

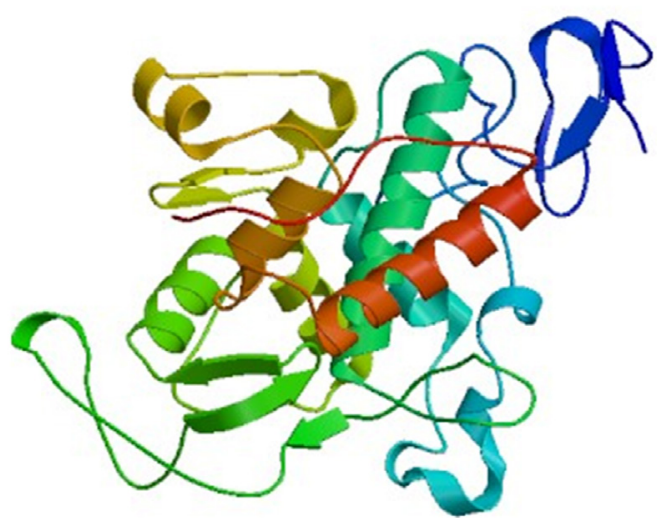

Figure 4. Tertiary structure model of HmCHT-2 protein.

The HmCHT-2 gene included a complete ORF that encoded a protein product of 312 amino acids (Figure 5). The protein, encoded by the HmCHT-2, consisted of an N-terminal signal peptide, chitin-binding domain (CBD) and catalytic domain, and belonged to class I chitinases. The bioinformatic analysis predicted that the molecular weight and theoretical 
isoelectric point of the HmCHT-2-encoded protein was $33.81 \mathrm{kU}$ and 8.42 , respectively. The instability index of this protein was predicted to be 34.13 , which indicated that this protein was stable. The total average hydrophilicity was -0.435 , suggesting the protein is hydrophilic. The analysis also predicted a signal peptide with a cleavage site between the 20 th and 21 st amino acids. Predictions of the transmembrane domains indicated that there was no transmembrane domain in the HmCHT-2-encoded protein and that the entire peptide chain was extra-membranous. The prediction of the subcellular localization indicated that HmCHT-2 mainly accumulates in the vacuole, suggesting that HmCHT-2 may contain a $\mathrm{C}$-terminal extension and could thus be characterized as a class Ia chitinase. The function of the C-terminal extension within class Ia chitinases is to guide the transportation of mature chitinases from the Golgi apparatus to the vacuole. The chitinases that do not contain the C-terminal extension will be secreted to the outside of the cell plasma membrane (Flach et al., 1992). The prediction of the secondary protein structure of HmCHT-2 indicated that $55.45 \%$ of the amino acids participated in the formation of random coils, $22.76 \%$ participated the formation of the $\alpha$-helix, $15.06 \%$ participated in the formation of extended structures and $6.73 \%$ participated in the formation of $\beta$-turns.

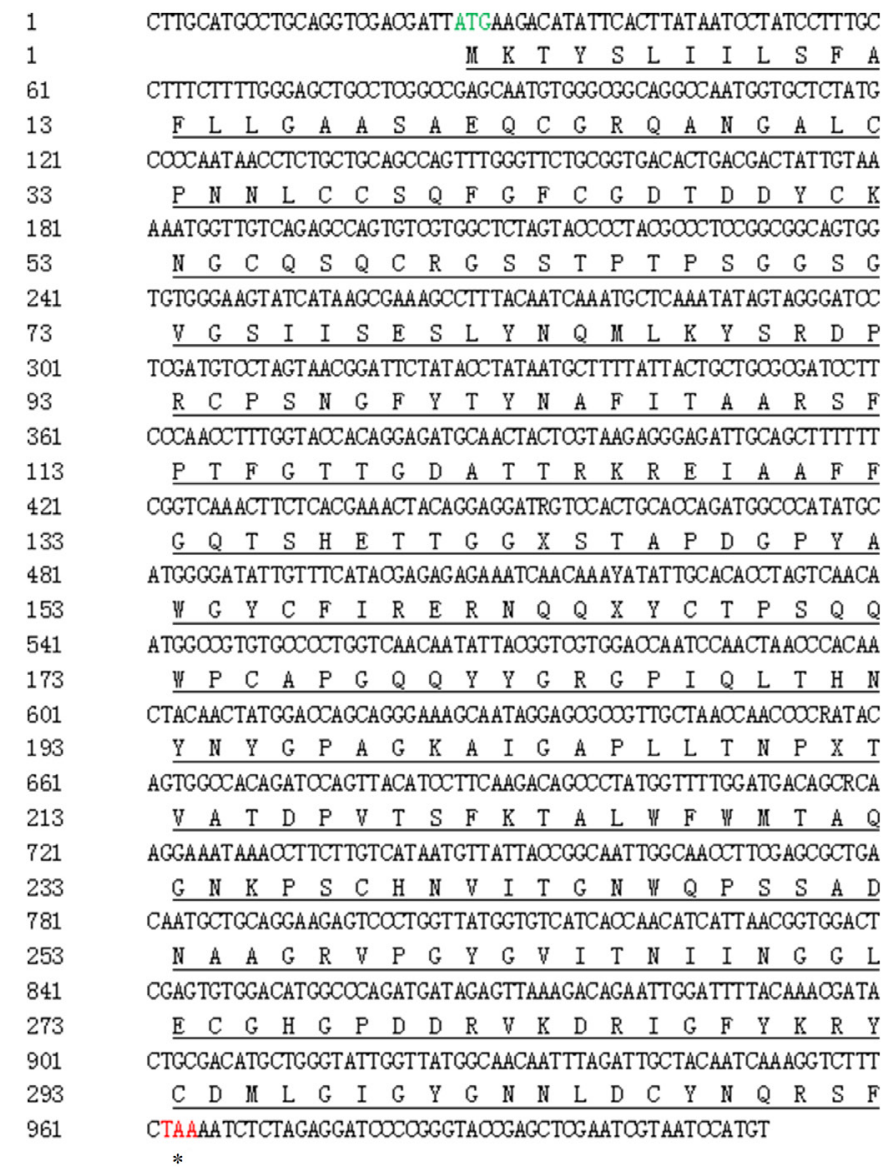

Figure 5. Nucleotide acid sequence and deduced amino acid sequence of HmCHT-2 (*termination codon).

Genetics and Molecular Research 16 (1): gmr16019085 
BLAST analysis showed that the HmCHT-2-encoded protein shared the highest similarity with endochitinase MCHT-2 of C. melo (NP_001284473.1). Phylogenetic analysis of the amino acids indicated that class I chitinases of different species have evolved from a common ancestor. The class I chitinase HmCHT-2 that we identified from the Hami melon belongs to same branch as C. melo, and is also closely related to cucumber (Figure 6).

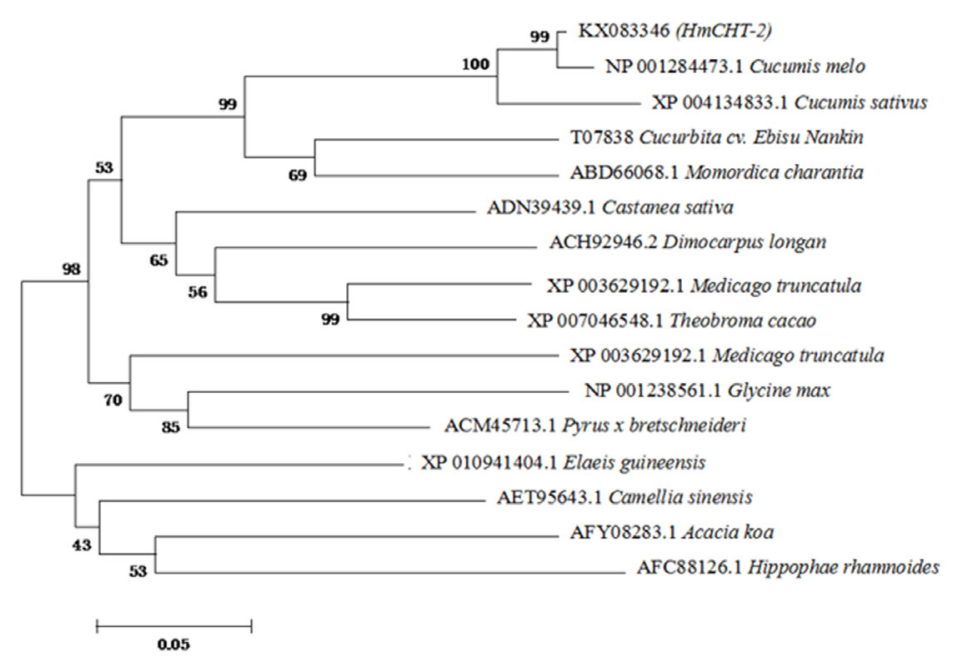

Figure 6. Neighbor-joining tree based on HmCHT-2 of Hami melon and other species.

\section{Gene expression analysis of $\mathrm{HmCHT-2}$}

The HmCHT-2-encoded class I chitinase-like enzyme may contribute to the defense against Penicillium infection in Hami melon. A preliminary real-time PCR study was performed to investigate the changes in expression levels of HmCHT-2 subsequent to infection with the Penicillium strain which we isolated from Hami melon. The results showed that in the control group (absence of Penicillium inoculation), the transcription level of HmCHT-2 was upregulated continuously during the first $24 \mathrm{~h}$, peaked at $24 \mathrm{~h}$ (which was 62-fold higher than $0 \mathrm{~h}$ ), and then dropped rapidly, reaching baseline level $(0 \mathrm{~h})$ at $48 \mathrm{~h}$. Thereafter, the transcription level increased only slightly. In contrast, in the experiments where Hami melon was infected with Penicillium, the transcription level of $H m C H T-2$ showed an overall increasing trend. While during the first $48 \mathrm{~h}$ the increase in transcription level of $H m C H T-2$ was slow, $60 \mathrm{~h}$ post-infection the transcription level of HmCHT-2 started to increase dramatically and peaked at $72 \mathrm{~h}$ post-infection; 545fold higher than at $0 \mathrm{~h}$. Thus, the time taken to reach peak level was delayed in the group infected with Penicillium. The incremental increases in the transcription level of HmCHT-2 of the infected group was less than that of control group during the first 36 $\mathrm{h}$, but increased significantly thereafter. Furthermore, the period of time for which high transcription levels were observed was also significantly greater than that of the control group $(\mathrm{P}<0.05$; Figure 7$)$. Therefore, we conclude that chitinases are rapid and effective enzymes involved in the response of Hami melon to Penicillium infection.

Genetics and Molecular Research 16 (1): gmr16019085 


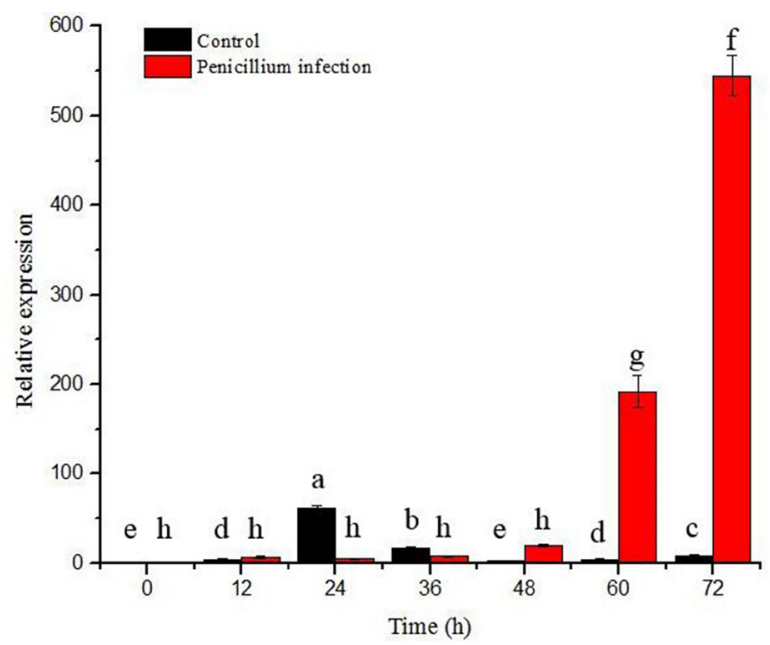

Figure 7. Relative expression of HmCHT-2 gene at different time points. Values are reported as means $\pm \mathrm{SE}$ $(\mathrm{N}=3)$. Different letters indicate significant difference $(\mathrm{P}$ value $<0.05)$.

\section{DISCUSSION}

Based on amino acid sequence homology, three-dimensional protein structure and the hydrolysis mechanism of the catalytic reaction, chitinases can be characterized into 7 classes (Grover, 2012). Of these, class I chitinases are only found in plants and have a structure consisting of an $\mathrm{N}$-terminal signal peptide domain, CBD and catalytic domain ( $\mathrm{Lu}$ et al., 2012). Class I chitinases can be further divided into basic class Ia and acidic class Ib. Class Ia contains a C-terminal extension domain which generally guides the protein to the vacuole (Flach et al., 1992), while class Ib is mainly located extracellularly. Protein structure prediction results in this study indicated that HmCHT-2 possesses all the typical structural features of a class I chitinase; including a 20 -amino acid signal peptide followed by a 40 -amino acid CBD, a catalytic domain after 140th amino acid, and six glycosylationbinding sites. ProtComp9.0 forecasts suggest that HmCHT-2 and $\mathrm{AC}=19171$ in the database have a high similarity, the score of HmCHT-2 located in vacuoles (Vacuolar) is 5.56, while the score of HmCHT-2 located in Extracellular is 4.43. Again, we use PredictProtein online prediction, the result shows that it is located in the vacuole, with a signal score of 65 . The specific location still need further experiments.

Chitinases play dual roles in the defense against fungal diseases. Exochitinases mainly function at the early stages of the infection process. When mycelium passes through plant cell walls, the interaction between exochitinases and the chitin in the mycelial cell wall leads to the release of inducers and the transduction of invasive signals. At a later stage, these particles bind to specific receptors, converting the initial innate immune response to an adaptive immune response. This response includes an increased expression level and synthesis rate of exochitinases, as well as increased induction of the synthesis of vacuole chitinases. The dramatic increase in exochitinases accelerates the production of inducers, therefore indirectly enhancing the invasive signal transduction (de A Gerhardt et al., 1997). When mycelium penetrates into intracellular spaces and damages the cells, the protoplast is disrupted and vacuole chitinases begin to exert anti-fungal functions by degrading the newly synthesized

Genetics and Molecular Research 16 (1): gmr16019085 
chitin chain and inhibiting fungal proliferation. In the response of plants to pathogenic attack, exochitinases might be the main mediator for the invasive signal transduction, while vacuole chitinases might be the main executor to inhibit fungal growth. Vacuole chitinases catalyze chitin more effectively than exochitinases, while exochitinases hydrolyze watersoluble chitin more effectively than vacuole chitinases. In the coevolution of plants and fungi, vacuole chitinases (especially Class I) have played important roles in plant defense mechanisms (Bishop et al., 2000).

Plants have developed a remarkable array of structural, chemical and protein-based defenses system (Simmons, 1994). Extensive research on the interaction between plant hosts and pathogens has revealed that chitinase-mediated defense, which is able to inhibit the growth of pathogens, belongs to the first type of four major biochemical reactions in plant defense against fungal invasion (Ebrahim et al., 2011; Keen, 1990). In this study, we investigated the expression level of one chitinase. The results indicated that the HmCHT-2 may related to Hami melon in defense against disease. To further understand how Hami melon responds to Penicillium, we aim to systematically elucidate the structural characteristics, precise subcellular localization and change in expression levels of additional chitinases.

\section{Conflicts of interest}

The authors declare no conflict of interest.

\section{ACKNOWLEDGMENTS}

Research supported by the National Natural Science Foundation of China (\#31360412).

\section{REFERENCES}

Bi Y, Tian SP, Guo YR, Ge YH, et al. (2006). Sodium silicate reduces postharvest decay on Hami melons: induce resistance and fungistatic effects. Plant Dis. 90: 279-283. http://dx.doi.org/10.1094/PD-90-0279

Bishop JG, Dean AM and Mitchell-Olds T (2000). Rapid evolution in plant chitinases: molecular targets of selection in plant-pathogen coevolution. Proc. Natl. Acad. Sci. USA 97: 5322-5327. http://dx.doi.org/10.1073/pnas.97.10.5322

Chen CK, Wang WS, Ning J and Gao YH (2012). Isolation and identification of the main pathogenic fungi from postharvest Hami melon in later period of storage. Adv. Mat. Res. 343: 1212-1216.

Cong F, Zhang Y and Dong W (2007). Use of surface coatings with natamycin to improve the storability of Hami melon at ambient temperature. Postharvest Biol. Technol. 46: 71-75. http://dx.doi.org/10.1016/j.postharvbio.2007.04.005

Dangl J and Jones JD (1998). Plant-microbe interactions. Affairs of the plant: colonization, intolerance, exploitation and co-operation in plant-microbe interactions. Curr. Opin. Plant Biol. 1: 285-287. http://dx.doi.org/10.1016/1369$\underline{5266(88) 80047-5}$

de A Gerhardt LB, Sachetto-Martins G, Contarini MG, Sandroni M, et al. (1997). Arabidopsis thaliana class IV chitinase is early induced during the interaction with Xanthomonas campestris. FEBS Lett. 419: 69-75. http://dx.doi.org/10.1016/ S0014-5793(97)01332-X

Ebrahim S, Usha K and Singh B (2011). Pathogenesis-related (PR)-proteins: Chitinase and $\beta-1,3$-glucanase in defense mechanism against malformation in mango (Mangifera indica, L.). Sci. Hortic. (Amsterdam) 130: 847-852. http:// dx.doi.org/10.1016/j.scienta.2011.09.014

Flach J, Pilet PE and Jollès P (1992). What's new in chitinase research? Experientia 48: 701-716. http://dx.doi.org/10.1007/ BF02124285

González FFNDC, Davey MR, Sanchez EC and Wilson ZA (2015). Conferred resistance to Botrytis cinerea in Lilium by overexpression of the RCH10 chitinase gene. Plant Cell Rep. 34: 1-9.

Graça I, Liang J, Guilherme M, Tavares P, et al. (2016). Cloning, overexpression and functional characterization of a class III chitinase from Casuarina glauca nodules. Symbiosis 70: 139-148. http://dx.doi.org/10.1007/s13199-016-0403-1

Genetics and Molecular Research 16 (1): gmr16019085 
Grover A (2012). Plant Chitinases: Genetic diversity and physiological roles. Crit. Rev. Plant Sci. 31: 57-73. http://dx.doi. org/10.1080/07352689.2011.616043

Guo XL, Bai LR, Su CQ, Shi LR, et al. (2013). Molecular cloning and expression of drought-induced protein 3 (DIP3) encoding a class III chitinase in upland rice. Genet. Mol. Res. 12: 6860-6870. http://dx.doi.org/10.4238/2013. December. 19.5

Guo Y, Liu L, Zhao J and Yang B (2007). Use of silicon oxide and sodium silicate for controlling Trichothecium roseum, postharvest rot in Chinese cantaloupe (Cucumis melo, L.). Int. J. Food Sci. Technol. 42: 1012-1018. http://dx.doi. org/10.1111/j.1365-2621.2006.01464.x

Keen NT (1990). Phytoalexins and their elicitors. ACS Symp. 439: 114-129.

Kombrink E, Schröder M and Hahlbrock K (1988). Several "pathogenesis-related" proteins in potato are 1,3- $\beta$-glucanases and chitinases. Proc. Natl. Acad. Sci. USA 85: 782-786. http://dx.doi.org/10.1073/pnas.85.3.782

Liu T, Tong JM, Ma WR, Wang J, et al. (2013). Separation and identification of main pathogen in Hami melon during cold storage. Mod. Food Sci. Technol. 8: 2030-2034.

Livak KJ and Schmittgen TD (2001). Analysis of relative gene expression data using real-time quantitative PCR and the 2- $\Delta \Delta$ Ct method. Methods 25: 402-408. http://dx.doi.org/10.1006/meth.2001.1262

Lu HC, Lin JH, Chua ACN, Chung TY, et al. (2012). Cloning and expression of pathogenesis-related protein 4 from jelly fig (Ficus awkeotsang Makino) achenes associated with ribonuclease, chitinase and anti-fungal activities. Plant Physiol. Biochem. 56: 1-13. http://dx.doi.org/10.1016/j.plaphy.2012.04.004

Ryals J, Uknes S and Ward E (1994). Systemic acquired resistance. Plant Physiol. 104: 1109-1112. http://dx.doi. org/10.1104/pp.104.4.1109

Shan CH (2015). Transcriptomics and Proteomics of Hami melon responding to Penicillium infection and change analysis of resistance-related enzymes. Jiangnan University, Wuxi.

Sharma N, Sharma KP, Gaur RK and Gupta VK (2011). Role of chitinase in plant defense. Asian J. Biochem. 6: 29-37. http://dx.doi.org/10.3923/ajb.2011.29.37

Simmons CR (1994). The physiology and molecular biology of plant $1,3-\beta$-D-glucanases and 1,3;1,4- $\beta$-D-glucanases. Crit. Rev. Plant Sci. 13: 325-387.

Stintzi A, Heitz T, Prasad V, Wiedemann-Merdinoglu S, et al. (1993). Plant 'pathogenesis-related' proteins and their role in defense against pathogens. Biochimie 75: 687-706. http://dx.doi.org/10.1016/0300-9084(93)90100-7

Taira T (2010). Structures and antifungal activity of plant chitinases. J. Appl. Glycosci. 57: 167-176. http://dx.doi. org/10.5458/jag. 57.167

Wu B, Zhang B, Dai Y, Zhang L, et al. (2012). Brittle culm15 encodes a membrane-associated chitinase-like protein required for cellulose biosynthesis in rice. Plant Physiol. 159: 1440-1452. http://dx.doi.org/10.1104/pp.112.195529

Genetics and Molecular Research 16 (1): gmr16019085 